\title{
A Novel Technique to Assess the Effect of Machining and Subsurface Microstructure on the Fatigue Performance of Ti-6Al-2Sn- 4Zr-6Mo
}

\author{
Daniel Suárez-Fernández ${ }^{1}{ }^{*}$, Bradley P. Wynne ${ }^{1}$, Pete Crawforth ${ }^{2}$, Katharine Fox ${ }^{3}$, and Martin Jackson ${ }^{1}$ \\ *DSuarezFernandez1@sheffield.ac.uk \\ 1) Department of Materials Science and Engineering, The University of Sheffield, Sir Robert Hadfield Building, Mappin St, Sheffield, S1 3JD, UK
}

2) Advanced Manufacturing Research Centre, Advanced Manufacturing Park, Catcliffe, Rotherham, S60 5TZ, UK

3) Rolls-Royce plc, PO Box 31,DE24 8BJ, UK

ABSTRACT

Aerospace titanium components are manufactured under the strictest standards in order to ensure the highest quality. To develop highly efficient machining processes, extensive research and investment is necessary. For the specific case of rotating titanium critical components, large quantities of forged workpieces are machined to determine the effects of the different machining parameters on tool wear characteristics and component structural integrity and performance. However, testing the different permutations of metal removal parameters and tool combinations is expensive and time consuming at the development stage. The novel approach developed and
presented here, enables the machining of smaller titanium parts that can be compared 1 -to-1 to parts extracted from industrial machined disc components. This approach not only reduces cost, but ultimately accelerates the research and development process due to more rapid feedback between different iterations of the machining parameters.

The proposed technique specifically replicates the face turning operation performed in rotational critical titanium components, such as compressor discs, using small coupons machined in a standard CNC machining centre. The machined coupons can be fatigue tested through a 4-point bending and microstructural analysis can be performed on the tested coupons to directly study the effects of the machining process on the surface and
underlying microstructure.

Keywords: Titanium alloys, Machining, Test specimens, Methodology, Experimental technique.

\section{Abbreviations}

\begin{tabular}{|l|l|l|l|}
\hline AMRC & Advanced Manufacturing Research Centre & $\mathbf{n}_{\mathbf{t}}$ & Number of teeth \\
\hline $\mathbf{a}_{\mathbf{p}}$ & Depth of cut & OD & Outer Diameter \\
\hline $\mathbf{a}_{\text {width }}$ & Width of cut & RPM & Revolutions per Minute \\
\hline CNC & Computer Numerical Control & $\mathbf{r}_{\text {tool }}$ & Tool radius \\
\hline $\mathbf{f}_{\text {rev }}$ & Feed per revolution & $\mathbf{v}_{\mathbf{c}}$ & Cutting Speed \\
\hline MRR & Material Removal Rate & $\mathbf{v}_{\mathbf{f}}$ & Table feed \\
\hline $\mathbf{N}$ & Rotational Speed & & \\
\hline
\end{tabular}

\section{Highlights}

Analysis of the face turning operation carried out to machine rotational critical aerospace components.

- Study of the possible machining processes and their variables to replicate the face turning effects in previously extracted coupons.

- Solution proposed to machine these coupons in a standard CNC machining centre using a boring head and adaptors.

Introduction

This paper presents a novel approach that replicates expensive and time-consuming face turning machining operation of disc profiles. The proposed technique developed at The University of Sheffield uses small coupons on a standard CNC milling machine. This enables the rapid assessment of machining and tooling parameters on subsurface damage and fatigue performance. The implementation of this technique will reduce research and development costs and provide the ability to test a wider range of development titanium alloys, machining parameters and development tools at an early stage. To generate confidence that the machining processes applied to these components will result in the desired mechanical properties, extensive testing must be performed. Titanium alloys are widely regarded as difficult to machine, due to their excellent mechanical properties at high reduction is a key point in manufacturing titanium alloys, particularly with the increase in titanium usage in aircraft, coupled with the project increase in aircraft orders (Figure 1). For example, it is estimated that more than (
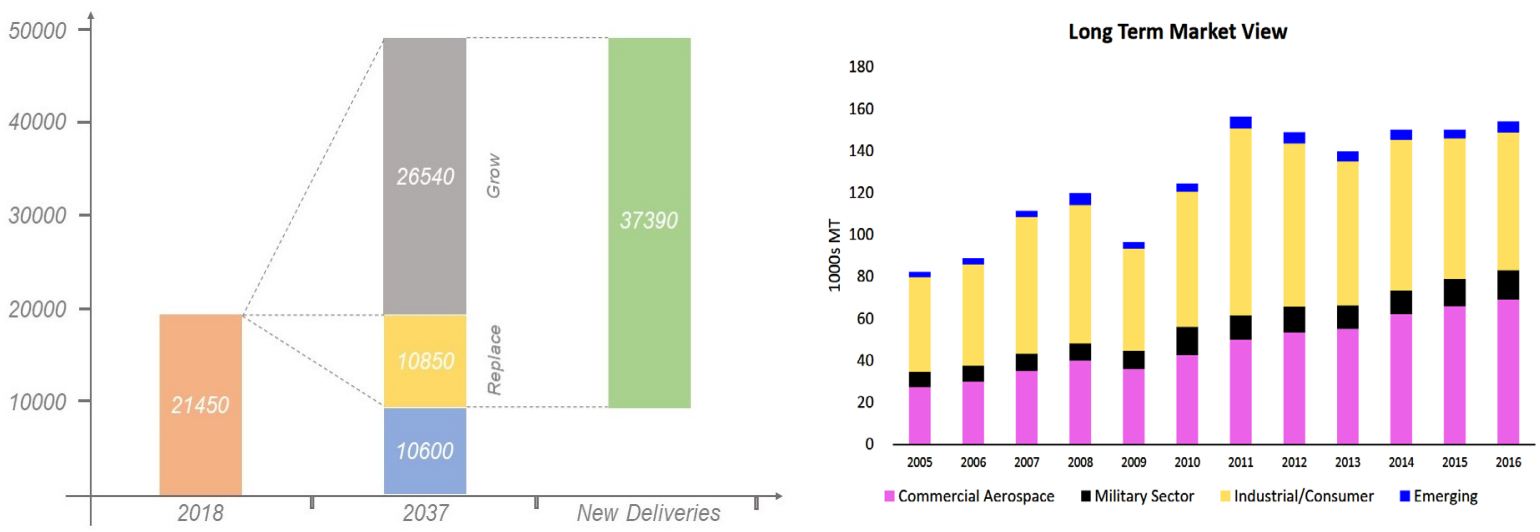

Figure 1. Number of new planes by 2037 [2] and Timet internal data for titanium market growth per sector in 2005-2016 range [3].

Moreover, titanium alloy components have to be extensively machined, when in some cases the machined volume to final component ratio (buy-to-fly ratio) can be about 10:1 [4] or $20: 1$ [5], meaning that only 5\% to 10\% of the original tanium forging is used in the final component, with the remainder of the billet being turned into swarf. This is supported by Seong et al. [4] where it is pointed out that improved machining techniques for titanium alloys will show the greatest reduction in cost for the finished component in the near and mid-term future. Lowering costs in machining technologies will drastically reduce the component unit price, making them more attractive in a very competitive sector. For example, aerospace companies typically spend of the order of $>£ 100$ million on milling operations per year. As machining a is key manufacturing step, a better understanding of the effect of metal

\section{Experimental Programme}

Process to replicate: Face Turning

The aim of this work is to replicate the face turning machining operation that transforms rectilinear forgings of alloy Ti-6Al-2Sn-4Zr-6Mo (Ti-6246), with a closer shape to the final object, into the final compressor disc. However, this is done in several steps divided into two main stages; roughing and finishing. However, the last finishing pass is critical, because it predominantly defines the surface topography and underlying metallurgical condition

(c) The Authors, published by EDP Sciences. This is an open access article distributed under the terms of the Creative Commons Attribution License 4.0 (http://creativecommons.org/licenses/by/4.0/). 

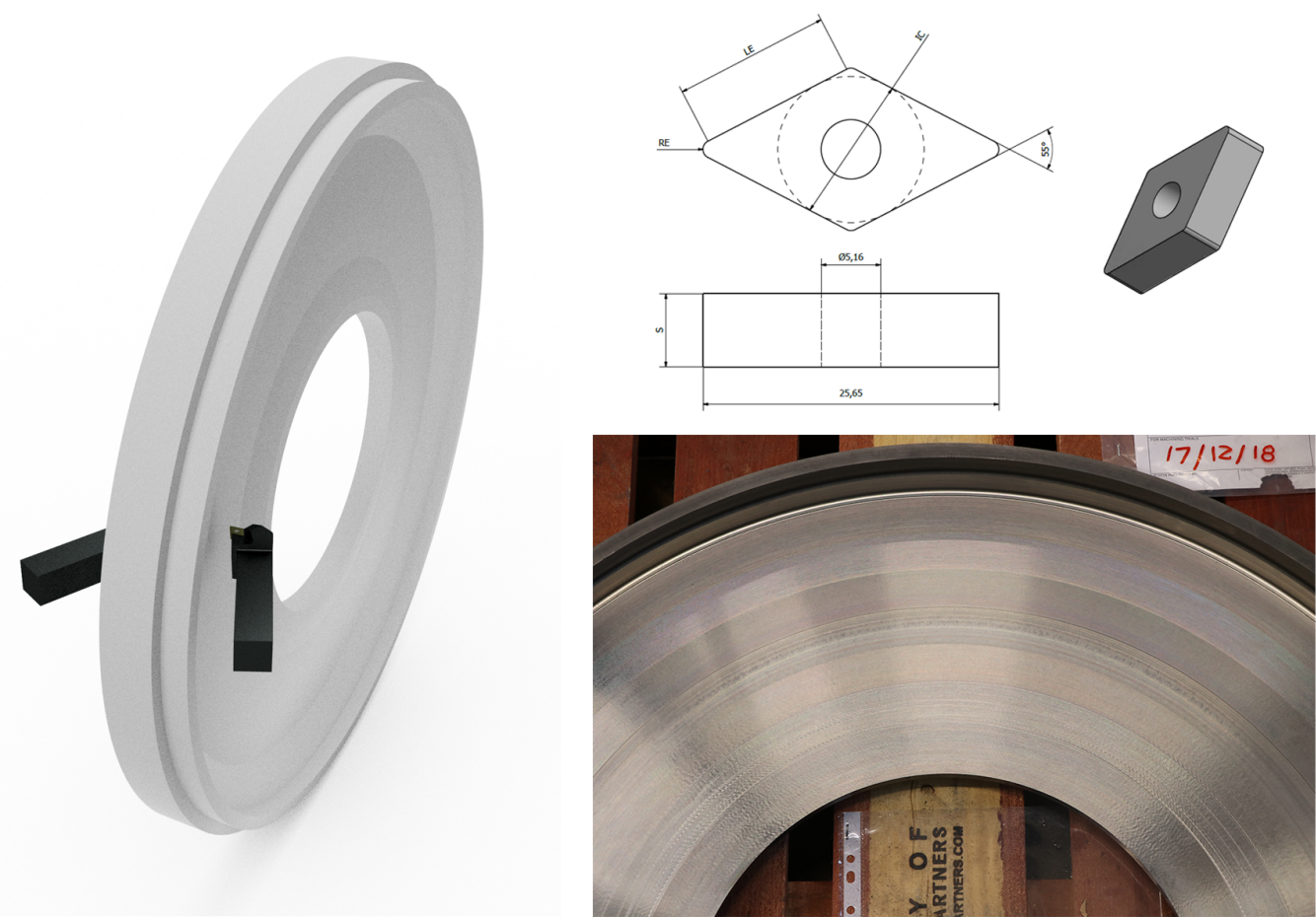
Figure 2. Double-sided face turning machining process carried out for machining Ti-6246 compressor discs (left), geometry of a T-Max® P Insert for turning DNMG 1506 08-23 H13A (top, right) and machining tracks in a face turning
titanium component (bottom, right).

The tool selected for this machining operation was an uncoated T-Max® P Insert for turning DNMG 1506 08-23 H13A made by Sandvik Coromant. The geometry and the dimensions of this tool are shown in Figure 2 and Table 1 .

Table 1. Dimensions of a T-Max® $P$ Insert for turning DNMG 1506 08-23 H13A.

\begin{tabular}{|c|c|}
\hline CODE & DIMENSION [mm] \\
\hline LE & 14.704 \\
\hline IC & 12.7 \\
\hline RE & 0.794 \\
\hline S & 6.35 \\
\hline
\end{tabular}

As the finishing pass is a light cut that has to be within the machinability range for titanium alloys, the machining conditions selected for this face turning operation are $0.5 \mathrm{~mm}$ of depth of cut (ap), $0.15 \mathrm{~mm} / \mathrm{rev}$ of feed per revolution ( $f_{\text {rev }}$ ) and a cutting speed $(\mathrm{Vc})$ of $50 \mathrm{~m} / \mathrm{min}$. The material removal rate $(\mathrm{MRR})$ for this set of parameters is calculated in Equation (1).

$\operatorname{MRR}\left[\mathrm{mm}^{3} / \mathrm{min}\right]=a_{p} \cdot f_{\text {rev }} \cdot V_{c}=0.5[\mathrm{~mm}] \cdot 0.15[\mathrm{~mm} / \mathrm{rev}] \cdot 50000[\mathrm{~mm} / \mathrm{min}]=$ $3750\left[\mathrm{~mm}^{3} / \mathrm{min}\right]$

It is also important to analyse the surface roughness that is obtained when machining a surface using this set of parameters. This is very important from the point of view of replicating a machining process, because the topography of the surface can affect the mechanical behaviour of a component when it is under operating loads. The machining tracks can act as stress concentrator points that ultimately could lead to cracking, which is
detrimental for component's performance. With the selection of the tool and the processing parameters, it is possible to estimate also the surface topographic conditions such as Ra, based on the estimation formulas by P. De Vos [6] as shown in Equation (2)

$R_{a}=\frac{f^{2} \cdot 50}{r_{\text {tool }}}=\frac{0.15^{2}[\mathrm{~mm} / \mathrm{rev}] \cdot 50}{0.794[\mathrm{~mm}]}=1.417[\mathrm{~mm}]$

Coupons to be machined

The coupons where the machining process is designed to be applied must be of similar dimensions to coupons extracted from the disc's diaphragm after the final face turning finishing operation. The extracted coupons have dimensions of $3.6 \times 19 \times 180 \mathrm{~mm}$. Due to the simple coupon geometry, using a turning lathe was not a viable option to replicate the disc finish face turning process, hence, a milling CNC centre was considered as a low cost and more widely available option.

Standard face milling using an indexable head

-Iteration 1:

One of the options that can be considered to replicate a face turning operation in a milling CNC machining centre, is using an indexable head with different tool inserts. This is a versatile option due to the vast range of suitable inserts that can be used. And therefore, the probability of matching a tool with similar characteristics to the turning insert is much higher. The selected indexable head was a CoroMill ${ }^{\circledR} 415$ face milling cutter $415-32 E H 25-05 H$ with an external diameter of $23.6 \mathrm{~mm}$ combined with a CoroMil ${ }^{\circledR} 415$ insert $415 \mathrm{~N}-050206 \mathrm{M}-\mathrm{M} 30 \mathrm{H} 13 \mathrm{~A}$.

The optimum machining parameters for this tool are shown in Table 2.

Table 2. Sandvik @ recommended processing parameters for using a CoroMill $₫ 415$ insert 415N-05 $0206 \mathrm{M}-\mathrm{M} 30$ H13A.

\begin{tabular}{|c|c|c|}
\hline Cutting edge length $[\mathrm{mm}]$ & $\mathrm{Vc}[\mathrm{mm} / \mathrm{min}]$ & $\mathbf{f}_{\mathbf{z}}[\mathrm{mm} / \mathrm{rev}]$ \\
\hline 3.8 & $34-36$ & $0.3-0.45$ \\
\hline
\end{tabular}

However, in order to avoid the machining marks and difference of surface topography generated by face milling: The process for this iteration uses the total cutting edge of the tool insert, for every longitudinal pass, instead the total circumference for machining the top surface. A schematic of the process is shown in Figure 3 . 


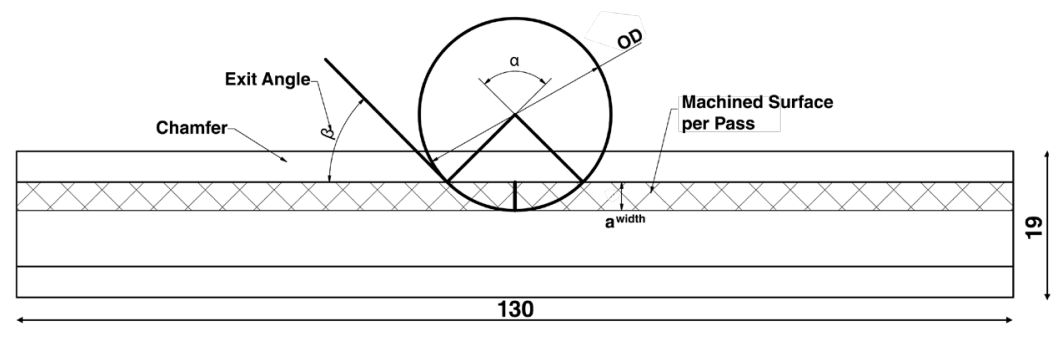

Figure 3. Geometric schematic of the area covered by the tool insert head with main variables highlighted.

In this case, the variable $\mathrm{a}_{\text {width }}$ is set as the maximum cutting length provided by the insert $(3.8 \mathrm{~mm})$. As the total width of the "non-chamfered" machining surface is $11 \mathrm{~mm}$, therefore, 3 passes are needed to machine the surface (Equation (3)).

Number of passes $=\frac{\text { Totalwidth }[\mathrm{mm}]}{a_{\text {width }}[\mathrm{mm}]}=\frac{11[\mathrm{~mm}]}{3.8[\mathrm{~mm}]}=2.89 \rightarrow \approx 3$ passes

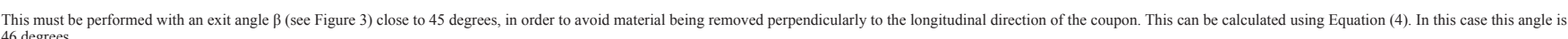

$a_{\text {width }}=\frac{O D}{2} \cdot(1-\cos \beta)$

Therefore, the machining conditions to replicate the face turning operation can be calculated for this specific case, such as the spindle speed, $\mathrm{N}_{\max }$ table feed $\mathrm{v}_{\mathrm{f}}$ and the MRR.

$N_{\max }[R P M]=36[\mathrm{~m} / \mathrm{min}] \cdot 1000[\mathrm{~mm} / \mathrm{m}] \cdot \frac{1 \mathrm{Rev}}{23.6[\mathrm{~mm}] \cdot \pi}=485.56 \mathrm{RPM}$

$v_{f}=n_{t} \cdot N_{\max } \cdot f_{z}=4[$ teeth $] \cdot 485.56[R P M] \cdot 0.45[\mathrm{~mm} /$ teeth $]=874[\mathrm{~mm} / \mathrm{min}]$

$M R R_{\text {milling }}=v_{f} \cdot a_{p} \cdot a_{\text {width }}=874\left[\frac{\mathrm{mm}}{\min }\right] \cdot 0.5[\mathrm{~mm}] \cdot 3.8[\mathrm{~mm}]=1660.6\left[\frac{\mathrm{mm}^{3}}{\text { min }}\right]$

Based on the calculations in Equations (5) (6) and (7), it is possible to conclude that this process will use a lower cutting speed and therefore a lower MRR than the face turning process it is replicating

-Iteration 2:

The second iteration proposed was to align the rotation axis of the indexable head at the centre of the longitudinal axis. The aim of this was to reduce the machining time and increase the MRR, however, the machining marks The second iteration proposed was to align the rotation axis of the indexable head at the centre of the longitudinal axis. The aim of this was to reduce the machining time and increase the MRR, how
on the top of the surface, Figure 4 (bottom), are not representative of a finish face turning operation. This surface topography occurs because the inserts cut through the whole rotation of the head.

Tilting the head can be a solution to this problem, specifically to the machining marks problem. A schematic of the tilted head is shown in Figure 4 . The main issue in this case was that the machined surface is not flat, due to the tilting of the axis. Moreover, the cross section of the machined surface would be curved, see Figure 4 (right). As one of the mechanical tests that will assess the machining process is a 4 -point bend test, the modification of the coupon cross section with stress concentrators is likely to significantly reduce the fatigue life, rendering the results not be representative of finish machined surface. Therefore, this $2^{\text {nd }}$ iterative machining process was deemed not suitable for replicating the conditions of a face turning operation.

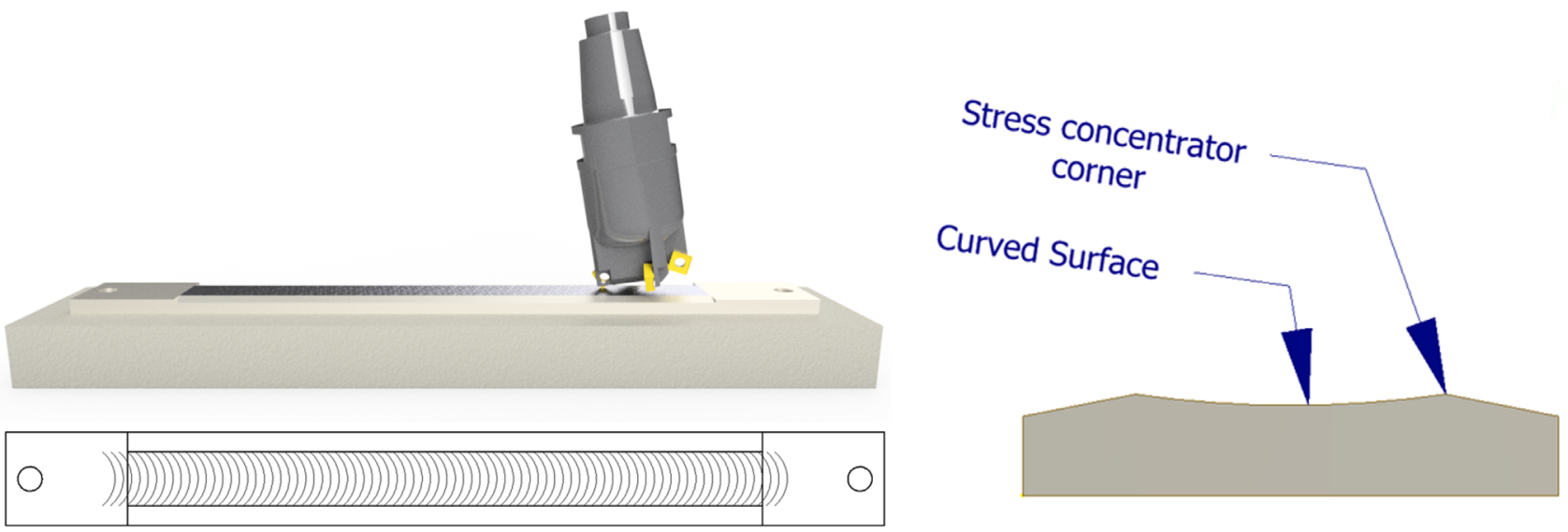

Figure 4. Schematic of the milling head tilted respect the surface to be machined (top left), the machining marks expected on the top surface (bottom left) and the modification of the cross section of the component due to the tilted axis (right).

Solution Proposed

The characteristics that the perfect replicating machining process are:

- Achieve the same:
- Cutting speed $V_{c}$
- Depth of cut $a$
- Feed per revolution $f_{\text {rev }}$

- Same material removal rate (MRR)

- Use same or identical turning insert 
- Same material/chip removal technique to face turning

The solution proposed fixes the coupon at the table and rotates the main spindle of the CNC milling centre with a boring head attached with a similar radius that the face turning operation to be replicated. Boring heads can be equipped with off-the-shelf adaptors that are specifically designed for turning inserts.

For this specific case, a Sandvik CoroBore ${ }^{\circledR} 825$ (2) combined with S20-R825SL32 020 and a head for turning T-Max P $^{\circledR}$ SL-PDJNR-32-15HP (3) (or the left handed equivalent). All this is assembled to a BT 40 / MAS-BT403 taper to connect the tool to the main spindle of the machine. The tool in this case is the same insert used for the turning operation, $T-M a x^{\circledR} \mathrm{P}$ Insert for turning DNMG $150608-23 \mathrm{H} 13 \mathrm{~A}$ (4). A numbered schematic and a

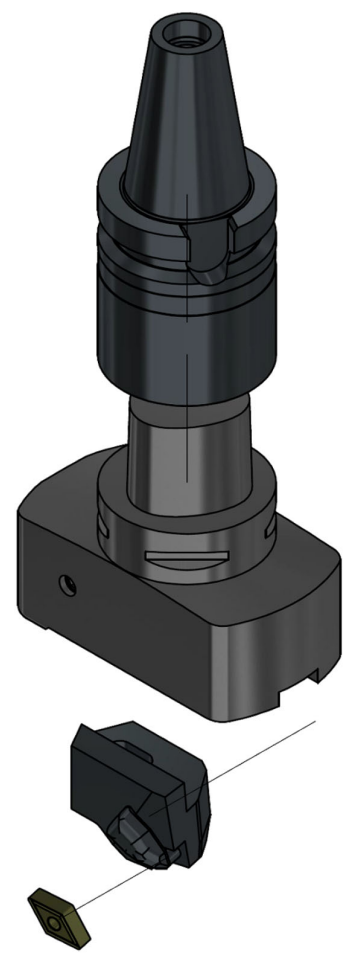

1

2
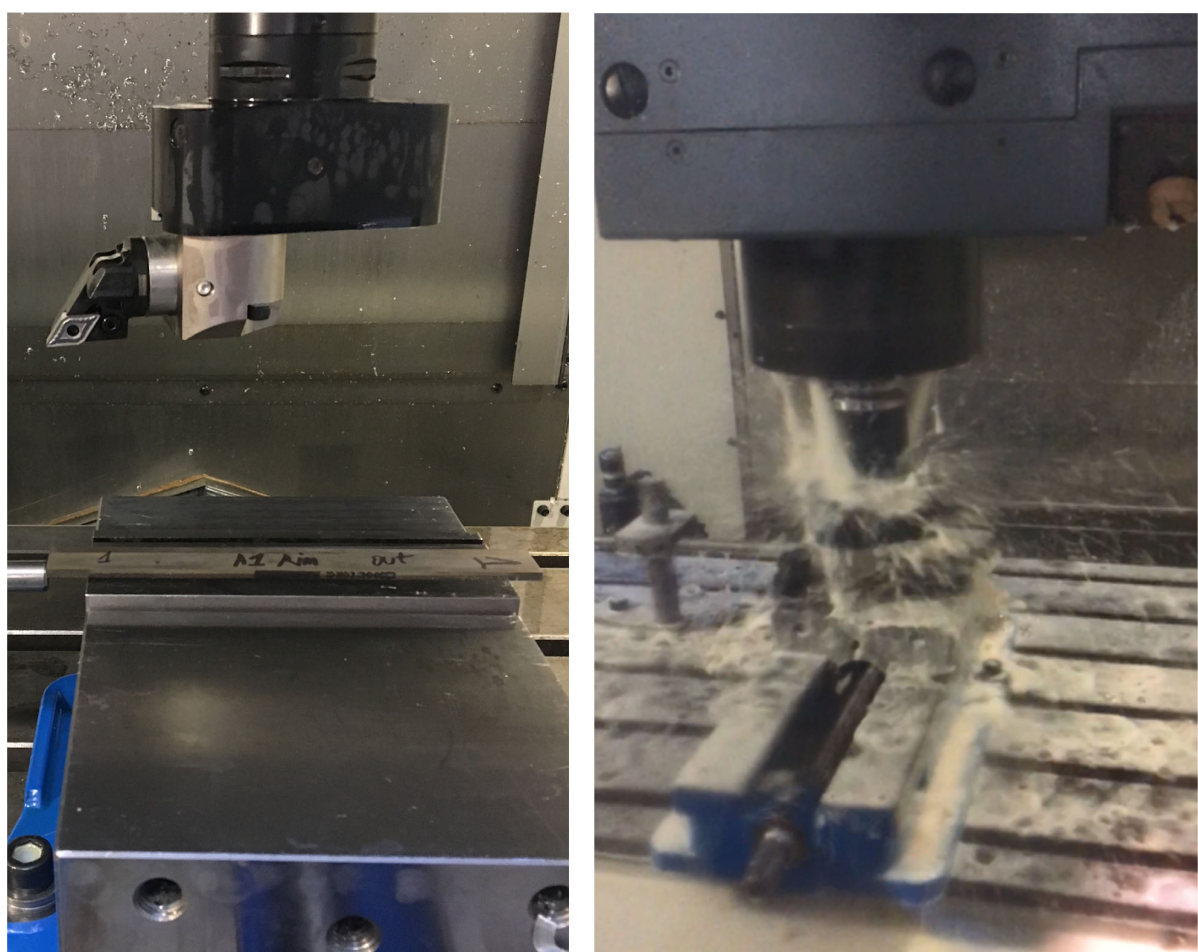

Figure 5. Exploded view of the boring head and all the adaptors installed (left), the set up of machining the coupons with the tool installed in the main spindle of the milling centre (centre) and, the machining process with flood coolant system (right) The turning radius was set to maximum for this configuration $(97.86 \mathrm{~mm})$. Comparison of the machining marks that will be produced during a (1) face turning operation and (2) machining of a coupons with the boring head, the
main difference will be the radius. However, if we consider the machine marks in the central testing area of the machined coupon, then the machined surface can be considered equivalent in both the large-scale finish face turning and small-scale coupon machining using the boring head, as schematically depicted in Figure
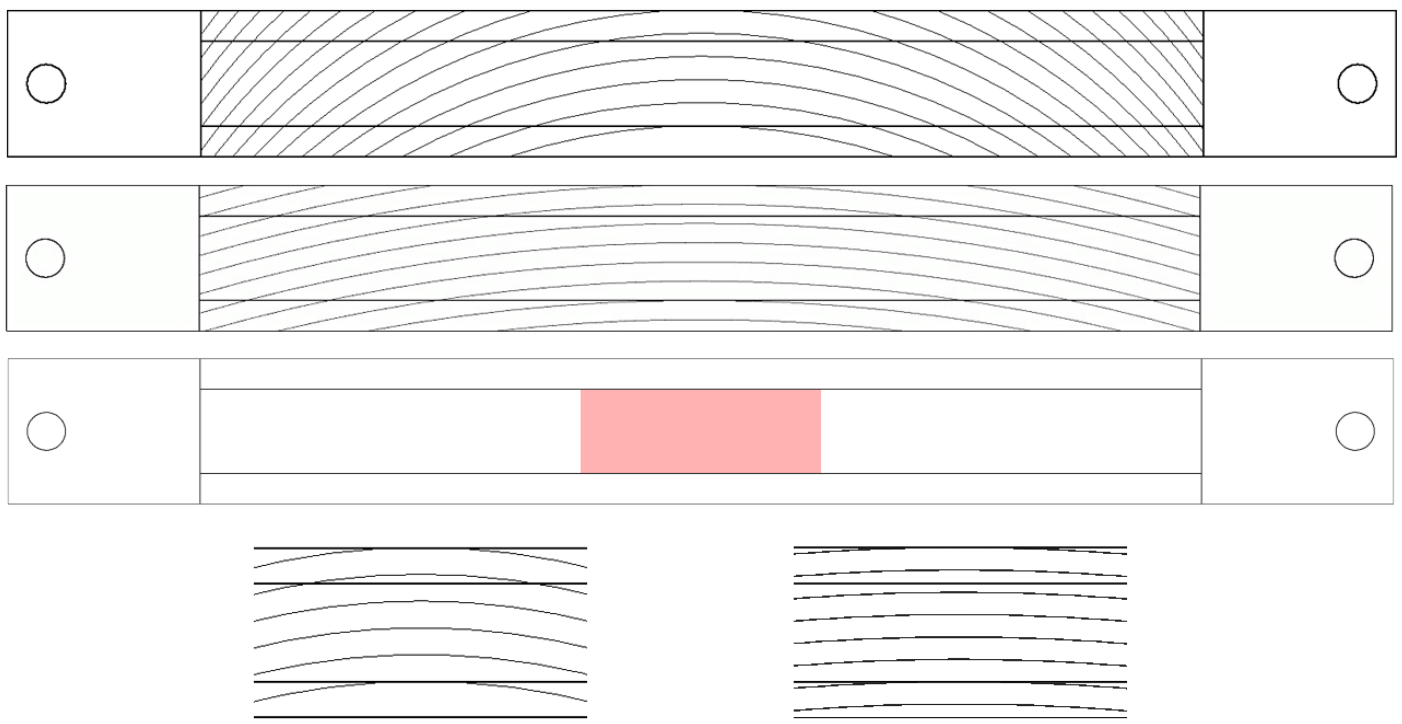

Figure 6. Schematic of the machining marks produced by the boring head set up with $195 \mathrm{~mm}$ diameter (top), a standard face turning operation with $460 \mathrm{~mm}$ of diameter (second), the coupon testing area highlighted in red (third) and a closer comparison of the area to be tested with both machining marks (boring head, bottom left and face turning operation, bottom right).

This approach enables the large-scale tool dimensions and finish machining parameters to be replicated, by calculating the table feed, depth of cut and spindle speed, which are inputted into the CNC milling controller. This is shown in Equations ( 8 ) and (9). The depth of cut ap is set at $0.5 \mathrm{~mm}$ by modifying the table-spindle distance.

$R P M=V_{c} \cdot \frac{1}{\text { Perimeter }}=50[\mathrm{~m} / \mathrm{min}] \cdot \frac{1}{2 \cdot \pi \cdot 97.86[\mathrm{~mm}] \cdot 10^{-3}}=81.32 \mathrm{RPM}$

feed $_{\text {table }}=$ feed $_{\text {rev }} \cdot R P M=0.15[\mathrm{~mm} / \mathrm{rev}] \cdot 81.32[\mathrm{RPM}]=12.2[\mathrm{~mm} / \mathrm{min}]$

Using these machining parameters provides the equivalent MRR compared to the face turning operation and the same material removal technique in a milling CNC machining centre. An image of a machined coupon is shown in Figure 7 , images at different magnifications are also shown. On the top, it is shown the equivalent face turned surface machined in an industrial facility. 

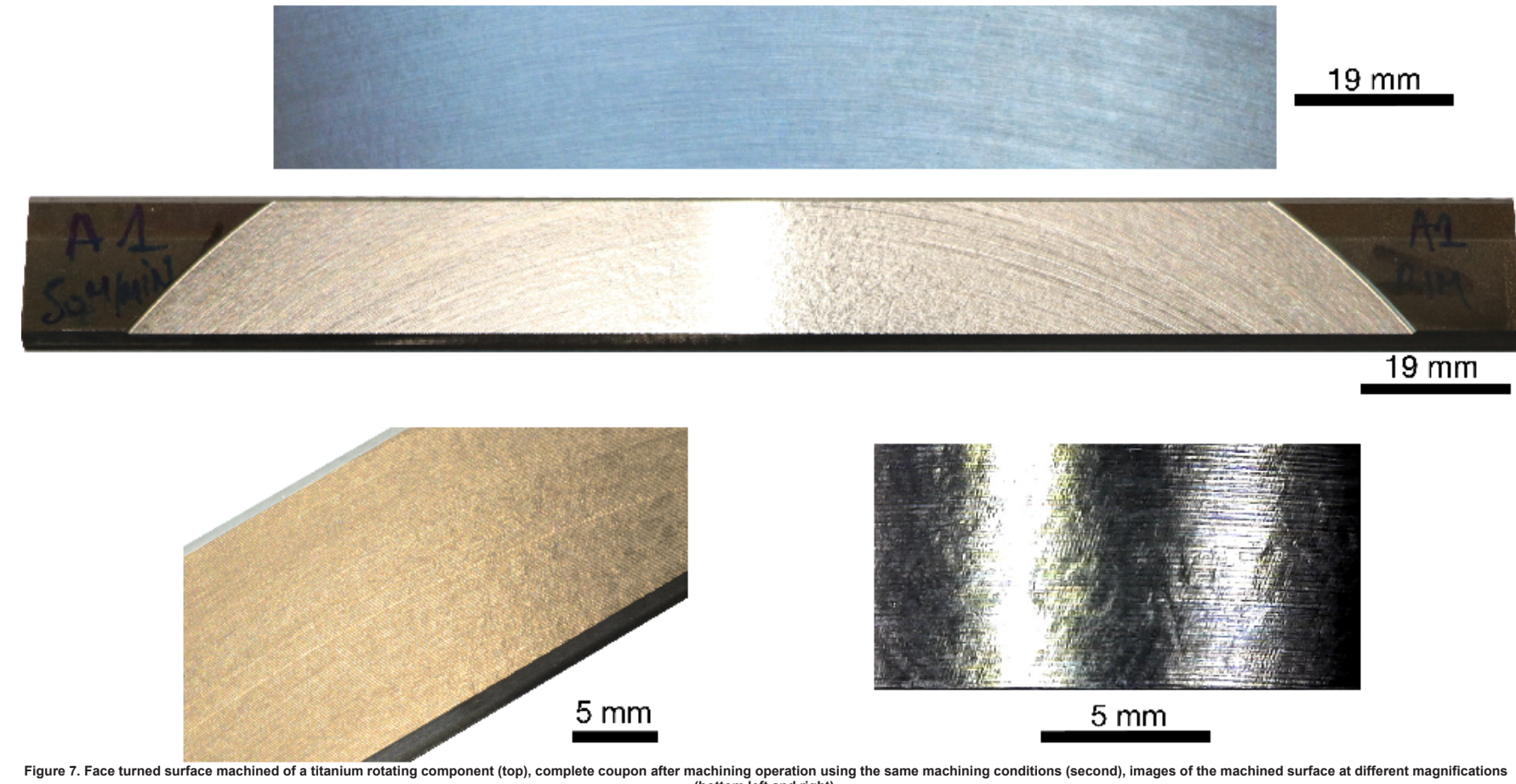

(bottom left and right).

\section{$\underline{\text { Conclusions }}$}

A novel technique has been designed and implemented in order to replicate costly face turning operations of large disc profiles using a standard CNC machining centre. The same machining conditions have been achieved on small titanium alloy coupons, using the same machining parameters and material removal rate.

The new approach presented in this paper has been designed with the goal of reducing resources necessary to assess the effect of different machining conditions for face turning operations applied to titanium alloy aerospace addition, the technique provides coupons ready for 4-point bend testing in order to evaluate the effects of the machining processes in components performance, by studying crack initiation and propagation mechanisms and fatigue life.

\section{Acknowledgements}

We would like to acknowledge EPSRC grant EP/L016273 Centre for Doctoral Training in Advanced Metallic Systems for supporting this research, and Justin Davies (Sandvik) and Phil Bell, Stephen Tyas and Amber Bennett (AMRC) for advice and assistance with the trials.

\section{References}

[1] R. Boyer and G. Welsch, C. E. W. Materials Properties Handbook: Titanium Alloys (1994).

[2] N. Lecca, (SVP Material \& Parts Procurement AIRBUS), International Titanium Association Singapore 2018, Titanium Asia 2018, Singapore February (2018)

[3] H. Seiner (TIMET), Non-Aerospace Demand: Trends and Forecasting, Titanium Asia 2018, Singapore February (2018)

[4] S. Williams et al., Wire + arc additive manufacturing, Materials Science and Engineering, Vol 32, Iss. 7, 641-647

[5] S. Seong et al. (RAND Corporation), Titanium Industrial Base, Price Trends, and Technology Initiatives, (2009) (https://doi.org/10.7249/MG789)

[6] P. de Vos et al. (SECO), Applied Metal Cutting Physics - Best Practice, (SECO TOOLS, Fagersta, Sweden, 2016) 